\title{
On the Network and the Principles of Freedom of Information
}

\author{
Zhang Huaimin, Shang Jingjing \\ Wuhan University of Technology
}

\begin{abstract}
With the rapid development of network technology, the human production mode, life style, and thinking mode have had the great change, meanwhile human values and morality are new changes. Network technology has created a brand of new social form and social network, which is an extension of the real social life. The purpose of this paper is to clarify the concept of a freedom of information analyzed by the principle of free network information. In this paper, theoretical and empirical combination is based on using multidisciplinary theory study from the perspective of moral cognition of this analysis. The problems of the network ethics which try to find out the method to solve the problem, standardize and strengthen the construction of the new good network ethics, purify network environment, and improve people's spiritual world and moral accomplishment, have important theoretical and empirical significance.
\end{abstract}

keywords: network information, freedom of information, principle

\section{Introduction}

Rousseau once said, "born free, but cannot in chains" (Jiang Yongfu 2007, 248). "Early modern thinker Machiavelli believes that freedom is artificial, and is a product of human action, rather than a standard of all natural status. Therefore, that a man is not free is not free to do whatever he can do, but he can make a selection from the possibility of the existence" (Li Figure, 2005). Because people live in the natural and social environment in which freedom is provided by the resource limited, advocating freedom is likely to be constrained by people, while people in free recourse is in inevitable conflict. In order to overcome this or avoid the conflict at last, people usually rational tell themselves they can't pursue freedom without borders, which is only a limited freedom. However, the human perceptual impulse is never to maximize the freedom, and it's often to make the person in a thirst for maximum freedom with real freedom of the contradiction between the limited.

\section{Connotation Network of Freedom of Information}

"Freedom of information" also known as "information disclosure," is a new trend after World War II at the international level rise; it originated in resolution in 1946 of the UN General Assembly. The conference resolution declared: "Freedom of information is a fundamental right of human and a freedom of the United Nations to pursue all cornerstone” (1948). The United Nations get through the Universal Declaration of Human Rights, in which states: "Everyone enjoys the freedom of opinion and expression; this right includes the freedom to hold opinions without interference, freedom, and ideas through any media regardless of frontiers to

Zhang Huaimin, Shang Jingjing, Dr. Marxism College, School of Marxism, Wuhan University of Technology, China; main research field: Media Ethics Research. E-mail: 751487980@qq.com. 
seek, receive, and impart information and ideas.” After that, "Freedom of information" has gradually evolved into a "field of freedom." On this basis, the content of freedom of information in many countries, including China, is also involved in the protection of constitutional rights and propelled through legislation, law enforcement, and justice at the domestic level.

In some ways, "freedom of information" is a specific individual freedom to seek, obtain, and impart information. Freedom through a concrete person with experience in obtaining the freedom of information activities was able to accumulate information into fields of activity in the general sense. So, what is the network information freedom? Since the generation of computer network technology, people put freedom of consciousness from the real world to the virtual world of the Internet, and as a new form of freedom of expression, "network freedom of information" has become the focus of the increasing attention. Some even thought that "no network there is no freedom; without freedom there is no network." No matter it is from the characteristics of the network itself or the general understanding of human society in terms of freedom of expression, freedom of network information should belong to the protected object to freedom of the expression. With the rapid development of today's world to promote a pluralistic, independent, free, and professional media form, freedom of information, especially in the development of computer network technology continues to expand. Research and discussion of information in the field of network information flow are very important.

From a general sense, the network of freedom of information mainly includes two aspects-freedom of expression and freedom of access to network information. Freedom of expression is the most important network activity in freedom of speech. But for now, the freedom of expression and the people of the widespread use of network activity "network spread freedom" is basically the same layer of meaning. Activities in the form of network information with a broader autonomy, without restraint, and therefore people are more eager to achieve the freedom of self-expression, the exchange of information in the network activities, and even that in the virtual world of the Internet, people can be achieved in the real world not achieve complete freedom, especially freedom of speech. The freedom of access to network information is in the form of a free people to achieve free access to the various types of information required in the network area of the desire, as long as it reflects the activities of people in the network information of the right information satisfies requirements. So virtual network space to give full freedom to do really exist, to answer this question, we first need to understand the information on the web is how to be free-flowing, which is the principle of information dissemination activities in the network and its characteristics.

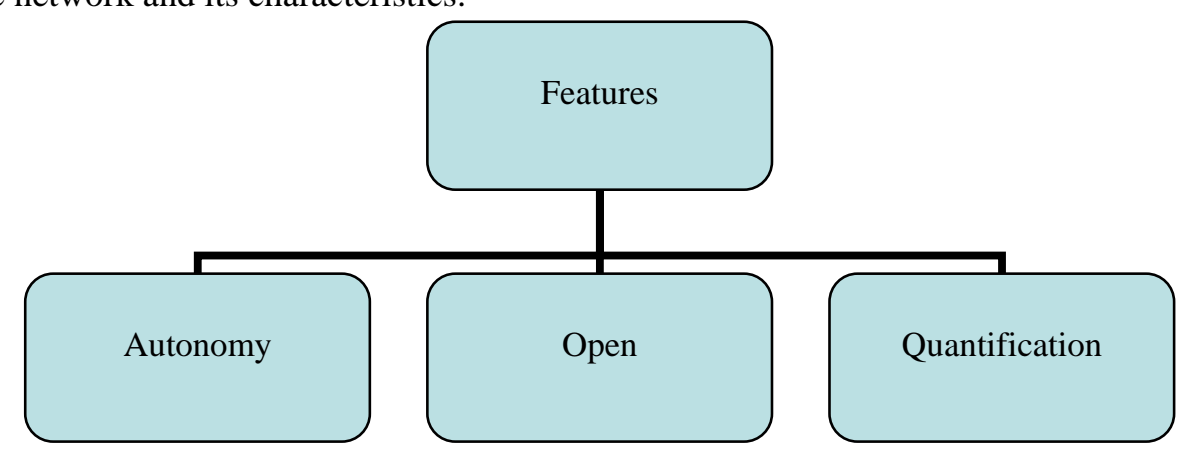

\section{Freedom of Information Dissemination Network Features}

Compared with traditional media, new media has become the main force in the dissemination of information. On the Internet, there are a variety of ways for users to get equal participation and freedom of 
speech. Those who can control the mass media and public opinion gradually retreated behind the scenes. Those who have been out of print layout work, can also directly pass the network for the public, no longer have to compete for the publication of the narrow territory. Therefore, we believe that the dissemination of information in computer networking feature has the following main aspects.

\subsection{Autonomy}

To some extent, a new generation of computer network information flow media subvert the traditional media functions. Its remarkable performance is the dissemination of information in a computer network with a broader autonomy characteristics. For example, from the "gatekeeper," this perspective of network information flows "gatekeeper" function when compared with traditional media tend to weaken, and its "agenda-setting" feature also decreases significantly. "Agenda-setting” is actually a "gatekeeper" continued and supplemented, which has two levels of meanings: First, select agenda, which is determined according to the criteria of newsworthiness and propaganda value to highlighting topics; second is setting the agenda to sort the topics selected before determining the weakness of the report layout or language used in the order details, and so on. In traditional information media, information actually has been through some kind of artificial screening or filtering purpose, which is abandoned in the agenda of those who cannot spread information and communication. Computer networks have tried to break the various ones in the course of the past, while information owners can be based on personal feelings, preferences, and wishes to choose the time and place, or even character roles and various services provided by the network for information delivery.

\subsection{Open}

Network Communication System is a highly open and globalized system. Open network of information dissemination is manifested to be most basic and straightforward features. We can say that the foundation of computer networks is free and open flow of information. Dissemination of information flow is also different from traditional communication networks which is important feature of the system. Network is a virtual realm, and anyone with the autonomy of people can express their views on the network, spread themselves as valuable and meaningful information, and other information in the network which have to interact, communicate, and so on. With the development of computer network and construction of the entire world into a big net, people in different regions or different countries via a network cable, optical fiber, and satellite channels are connected to the network. No matter what culture, religion, gender, age, and occupations, it is available for the acquisition and dissemination of valuable information on their own to re-create their own living conditions, so they do not even need to distinguish between the real situation and the specific identity of the people and events of the network. Network technology allows that people's identities can be turned into a string of characters in the network. Through these symbolic virtual information channel, people can freely open access to domestic and international sites, vast amounts of information without the need to consider impeding too much time and space. Meanwhile through the network, they can be friends with strangers, and chat or discuss the issue. What is more, you can easily get government or personal information in certain public official website. It can be said that if they lose the characteristics of this open, the dissemination of network information may also simply be a traditional information into an electronic symbol, and it will never have such a profound impact on people's social life. 


\subsection{Quantification}

With the rapid development of computer network technology, network information dissemination capacity exceeds the amount of the spread of print media, showing sea quantifiable characteristics. Spreading capacity, newspaper whatever page increases, radio, and television could increase the channel. Moreover, additional channels and expanded edition are also constrained by a variety of objective circumstances. Due to the spread of traditional print media, capacity is limited by space and time, which makes the editors often have to have a very important and valuable information on some of the same reluctantly part. Network information for its independent and open-oriented features, making its dissemination capacity is virtually unlimited. Computer network to achieve a shared resource for all networked computers, is far from any kind of its richness comparable traditional media. Even the dissemination of information on the network set up a review system , as long as the network by finding a keyword search engine searches out that hundreds of thousands of network information easily edit the network information which will not be deleted because of concerns fit Some news. Furthermore, the computer has excellent memory function, that is to say, a small hard drive will be able to load the contents of a library of all books. Computer network is also able to update information content, while all existing information are saved for users to retrieve and use. Therefore, when compared with traditional media such as newspapers, radio, and TV, network with sea quantitative information capacity and ability to communicate, says the Internet is the largest library in the history of mankind.

\section{The Main Principle of Free Flow of Information Should Follow the Network}

Since the network in the form of free flow of information is not unlimited freedom, for the free flow of information network, what principles to follow in order to maximize protection of their freedom? As the "government holds more than $80 \%$ of the whole society of information resources" (Toby Mandel 2011), it is the largest owner of public information and control. So government information as a public resource must flow freely, and the government has the responsibility to publish an obligation conscious information in its possession in order to make better use of the citizens. From the perspective of government protection of civil liberties, the right to access to information and freedom of information in any public protection is an important criterion that we must pay attention to. Information flows in the network should follow the following main principles.

\begin{tabular}{ll}
\hline No. & principle \\
\hline 1 & The principle of maximum disclosure \\
2 & Obligation to publish information principles \\
3 & Limit the scope of "exception" principle. \\
4 & Principles to facilitate the flow of information \\
\hline
\end{tabular}

\subsection{The Principle of Maximum Disclosure}

The principle of openness network information flow network is the core meaning of the right to information. This means that the breadth of the scope of the right to information networks, involves not only the object-related information, the scope, and variety of institutions, but also the appropriate rights which may make individual requirements. This principle is based on this assumption: All information on government and other public bodies are to be open to citizens, but only for the legitimate public, personal interests must be 
given priority to prevent a serious threat to go beyond the assumption. That is, only when very few cases involve confidential content or public safety-related and other exceptions, everything else should be to maximize the information available to the public, as well as the network information flow. Currently, many of the principles of law are clearly defined and explained. "The United Nations Guidelines" pointed out: "Public institutions have the obligation to publish information that every public has a corresponding right to receive information; information includes all records of public bodies controlled, but not limits any protection” (Toby Mandel 2011). In the international community “Joint Declaration” and "African Declaration” also stressed: "Public agencies access information not for themselves but for the benefit of hosting public information" (Huang Man 2009). Considering the right to obtain information, the government should follow the principle of maximum reasonable network management and control the flow of information content, so the way to protect the public can be more equitable access to a wider range of information freedom.

\subsection{Obligation to Publish Information Principles}

In the process of the network information flow, citizen access to relevant information for passively. Government agencies who understand and manage network information should have the nature of public goods. This tax "from the people, giving back to people" has a similar place, and the government should be its own administrative public information promptly announced to the people. Therefore, the relevant public bodies should take the initiative to publish and disseminate critical information to ensure that the public can access information effectively to their needs. Even in the case, public did not get any requests, which is an important obligation of government and other public bodies. Ours is a right to democracy and the rule of law, for that the country belongs to the people, but in the form of State and Government of the social contract on behalf of the partial exercise of the rights of citizens, the people are the real masters of our country, owner, and national sovereignty providers, and government agencies will only represent the people managing public affairs agency. Government has the most information-rich society public institutions. If it is too controlled, closed network information flow, so a lot of information will only flow between networks within government agencies, and ordinary citizens are deprived of the right to information, informed rights, and other legal rights (Toby Mandel 2011). To some extent, there is still the obligation to obtain the degree of network information resources. With the continuous increase in the amount of information covered by the network of communication, especially the use of new technology will release more information and disseminate information more convenient smoothly and timely. Relevant departments should timely apply technology, making the network information timely updated. The public can easily get the information you need. Depth and breadth of the work of the Government to ensure the free flow of network information to carry out and conduct will be directly related to the degree of utilization of the development of society as a whole network of information resources related to the implementation of each citizen and social organizations legitimate right to freedom of network information; therefore, government and other relevant public institutions have a responsibility to promptly reach out to the public disclosure of such information network to ensure smooth network free flow of information, making it as large as possible within the range used by more people to meet the public's needs of multifaceted and multi-level network information.

\subsection{Limit the Scope of "Exception” Principle}

Any establishment of social activities are legal or institutional basis, without any constraints, then freedom 
will lose its original meaning. The same, the government and other public institutions to protect network free flow of information, ensure that network information to maximize the public is not without reservation. Anything beyond the limits of the law will affect the rights and interests of the free flow of information and the public network information "exceptions" cases, usually to carry on the reasonable control or limit. We should limit the disclosure of certain information, such as these which is not conducive to the public interest or involve state secrets, the network information of commercial secrets, and personal privacy. Limit must be "exceptions," which has been confirmed by law in advance. The government information disclosure regulations of our country has special provisions, and the administrative organ may not harm public interests or public involving state secrets, commercial secrets, and personal privacy information. But on the other hand, the legal "exception" rule is extremely complex, and too wide or too tight constraints on public security of network information weight method are extremely adverse. In a confidential manner in full legal, government must take care to protect the information, and the basis of other information should be released. The government public institutions, such as to the scope and content of "exception" of the situation a reasonable limit, otherwise will cause the network information due to that "exception" is too much to normal flow freely. Therefore, the "limit 'exceptions' scope" free flow of information in a network of this principle is to ensure that in some way or in some cases the right of citizens to freedom of information is necessary and reasonable restrictions .

\subsection{Principles to Facilitate the Flow of Information}

In addition to publishing information, the government needs to take the initiative, but also needs to establish a system of proactive, coherent, and practical operational procedures. We must correctly handle the spread of mobile network information to follow the principle of free flow of information network. For example, the Council of Europe's recommendation on the establishment of such a program has a very detailed description, which presents a series of specific criteria. Meanwhile, decision-making within the government should establish a relatively independent review and supervision system. If the government refuses to disclose the information or no network in the prescribed manner, procedures accurately and timely processing of applications network will access to information, then the people have the right to appeal to an independent oversight body. According to reliable information recording, tracking the right to information is guaranteed, ultimately making the information public get a reasonable solution to this problem. In this case, the public agency must bear for refusing to open and lift restrictions on freedom of network information flow of legality and rationality and cause inconvenience to the impact on people's responsibility. Therefore, only by earnestly following the principle of free flow of information networks can government departments develop better policies, which ultimately ensures that the interests of people can be achieved.

\section{Conclusion}

Hence, Freedom of information not only rely on a sound network legal system, but also rely on moral self-discipline. It establishes the principle of network information and scientific beliefs and moral self-discipline. Voluntary recognition and practice of morality truly enjoy the freedom of the network society.

\section{Works Cited}

Jiang, Yongfu. "Freedom of Information and limit research.” Beijing: Social Sciences Academic Press, 2007. 248.

Li Figure. “From 'natural liberty’ to ‘social freedom.”’ Beijing: sociologist cafe (4) 2005. 
Hayek. “Law, Legislation, and Liberty.” Deng translated, Britain: Encyclopedia of China Publishing House, 2003. 165.

Yan Geng. “Internet ethics.” China: Beijing Publishing House, 1998. 201.

Lifeng, Yan. "Ethics in Internet freedom.” network Fortune 2008. 13.

Chen Juan. "freedom of information dissemination network Internet-based research.” graduate thesis, Shanghai: East China Normal University, 2004. 23.

Toby Mandel. “Freedom of Information-multinational comparative law.” Beijing: Social Sciences Academic Press, 2011 Section 41.

Toby Mandel. "Freedom of Information—multinational comparative law.” Beijing: Social Sciences Academic Press, 2011 Section 42.

Huang Man. “Information access government information disclosure under the right research.” graduate thesis, East China Normal University, 2009.

Toby Mandel. “Freedom of Information—multinational comparative law.” Beijing: Social Sciences Academic Press, 2011. 51. 